\title{
A site-sensitive quasi-in situ strategy to characterize Mo/HZSM-5 during activation
}

Ina Vollmer ${ }^{1}$, Nikolay Kosinov², Ágnes Szécsényi ${ }^{1,3}$, Guanna Li ${ }^{1}$, Irina Yarulina ${ }^{4}$, Edy Abou-Hamad ${ }^{5}$, Andrei Gurinov5, Samy Ould-Chikh ${ }^{4}$, Antonio Aguilar-Tapia ${ }^{6}$, Jean-Louis Hazemann ${ }^{6}$, Evgeny Pidko ${ }^{3}$, Emiel Hensen², Freek Kapteijn ${ }^{1}$, and Jorge Gascon ${ }^{1,4}$

${ }^{1}$ Catalysis Engineering, Chemical Engineering Department Delft University of Technology, Van der Maasweg 9, 2629 HZ Delft, The Netherlands.

${ }^{2}$ Schuit Institute of Catalysis, Laboratory of Inorganic Materials Chemistry, Eindhoven University of Technology, P.O. Box 513, 5600 MB Eindhoven, The Netherlands.

${ }^{3}$ Inorganic Systems Engineering, Chemical Engineering Department Delft University of Technology, Van der Maasweg 9, 2629 HZ Delft, The Netherlands.

${ }^{4}$ King Abdullah University of Science and Technology, KAUST Catalysis Center, Advanced Catalytic Materials, Thuwal 23955, Saudi Arabia

${ }^{5}$ King Abdullah University of Science and Technology, Core Labs, Thuwal 23955, Saudi Arabia

${ }^{6}$ Inst. Néel, UPR 2940 CNRS - Univ. Grenoble Alpes, F-38000 Grenoble, France

\begin{abstract}
The active sites on the methane dehydroaromatization (MDA) catalyst Mo/HZSM- 5 are very hard to characterize, because they are present in various geometries and sizes and only form under reaction conditions with methane at $700 \stackrel{\circ}{\circ}$. To address these issues an experimental strategy is presented that enables distinguishing different active sites for MDA present on Mo/HZSM-5 and helps determining the Mo charge, nuclearity and chemical composition. This approach combines a CO pretreatment to separate the active Mo site formation from coke formation, quasi-in situ spectroscopic observations using DNP, ${ }^{13} \mathrm{C}$ NMR, CO IR and theory. This allows the discrimination between three different types of active sites. Distinct spectroscopic features were observed corresponding to two types of mono- or dimeric Mo (oxy-)carbide sites as well as a third site assigned to $\mathrm{Mo}_{2} \mathrm{C}$ nanoparticles on the outer surface of the zeolite. Their formal Mo oxidation state was found to be between 4+ and $6+$. Dynamic nuclear polarization (DNP) measurements of samples carburized in $\mathrm{CO}$ as well as in $\mathrm{CH}_{4}$ confirm the assignment and also show that accumulated aromatic carbon covers the bigger Mo nanoparticles on the outer surface of the zeolite, causing deactivation. It was previously observed that after an initial period where no desired products are formed yet, benzene starts slowly forming until reaching its maximum productivity. Direct observation of the active site with ${ }^{13} \mathrm{C}$ NMR confirmed that Mo-sites do not transform further once benzene starts forming, meaning that they are fully activated during the period where no desired products are observed yet. Therefore the slow increase of the benzene formation rate cannot be attributed to a further transformation of Mo sites.
\end{abstract}

\section{Keywords}

Methane dehydroaromatization, Mo/HZSM-5, DNP SENS, CO IR, ${ }^{13} \mathrm{C}$ NMR, Mo (oxy-)carbide, Mo2 $\mathrm{C}$, monomeric species, dimeric species, well-defined species

\section{Introduction}

Direct, non-oxidative conversion of methane provides an alternative way to obtain aromatics. If this process could be brought to commercialization, it could compensate for the decrease in production of aromatics from naphtha crackers of which many, especially in the US, are currently revamped to gas crackers [1]. Shale gas is available and cheap, which makes it an attractive feedstock [2]. Because of that, developing an active and stable methane dehydroaromatization catalyst has gained a lot of research interest since this reaction was shown to be possible over a Mo/HZSM-5 catalyst [3, 4]. Still today Mo supported on HZSM- 5 remains the most researched system, because of its superior performance. It is not fully understood why this particular system performs so well and how the structure of the Mo active site looks like exactly.

Pinpointing the active site on a heterogeneous catalyst and its full spectroscopic characterization have rarely been achieved, because of the plethora of sites with different geometries and nuclearities one 
has to consider [5]. At the same time, only a small fraction of these sites is responsible for all catalysis [5-7] and to spot which ones are most active is a challenge. Developing a structure-activity relationship for the methane dehydroaromatization (MDA) is further complicated because the active sites form at reaction conditions in an initial period where no desired products are observed yet [8-14]. Because of this, measurements need to be performed operando or quasi-in situ to characterize the active site, which is challenging, mostly because of the high reaction temperature of 700 to $800 \stackrel{\circ}{\circ}$. During the activation period, Mo was shown to reduce and carburize [8]. However, there is no agreement about the degree of reduction and carburization and several species have been proposed to constitute the active site: $\mathrm{MoC}, \mathrm{Mo}_{2} \mathrm{C}$, coke modified $\mathrm{Mo}_{2} \mathrm{C}$ [15], $\mathrm{Mo}_{2} \mathrm{C}[10,16]$, any kind of $\mathrm{Mo}^{6+}$ and partially reduced oxide $\mathrm{MoO}_{(3-x)}[17,18]$. Gao et al. and Khan et al. performed DFT calculations to determine the dehydroaromatization activity of fully carbidic clusters with the formula $\mathrm{Mo}_{2} \mathrm{C}_{\mathrm{x}}$ and $\mathrm{Mo}_{4} \mathrm{C}_{\mathrm{x}}[19,20]$. Since these are only a few of many possible structures Mo can take on at reaction conditions, to really get valuable insight from such calculations, more direct evidence on the nuclearity and size of the Mo sites is needed. XAS [13] and Operando XAS [9, 14, 21] have been performed to detect Mo carbide formation, but since it is a bulk technique only an average over all active sites present can be obtained $[6,22]$.

${ }^{95}$ Mo NMR, similar to XAS also directly probes the electronic state of Mo, but leads to a very broad signal that does not allow to determine the nuclearity, stoichiometry or location of Mo inside the zeolite channels $[23,24]$. EPR can also directly probe, but unfortunately does not lead to much insight on the (oxy-)carbidic species either [14, 25, 26].

Gao et al., using UV Raman, were able to gain valuable insight on the location and nature of the Mo oxidic species before reaction [27]. The bands for oxidic species disappeared upon contact with methane at reaction temperature, which lead them to speculate about the formation of Mo (oxy-)carbides. These Mo (oxy-)carbides themselves however cannot be detected by UV Raman, also demonstrating the limitations of this technique to elucidate the exact nature of the active site.

Other techniques often used to determine the structure of supported organometallic compounds, like NMR and IR [28] are difficult to apply, since the catalyst experiences severe coking already during the activation period. This means that the carbon signal in ${ }^{13} \mathrm{C}$ NMR is obscured and absorption of the sample is very high, leading to weak infrared (IR) signals. Additionally, access to some of the active sites could be blocked by coke and therefore renders it inaccessible to probe molecules.

CO IR spectroscopy can be used to determine the oxidation state, nuclearity and uniformity of metal cations and to probe the acidity of the zeolite [29-37]. Mo is present in its oxidized form on the assynthesized catalyst and does not adsorb $\mathrm{CO}$. The more reduced a Mo species is, generally, the lower the vibrational frequency of the $\mathrm{CO}$ adsorbed on the Mo species [35, 38]. Information about the nuclearity of metal species can also be obtained from the full width at half maximum (FWHM) of the absorbance band [36, 37]. The broader the band, the bigger the metal cluster, because a bigger cluster offers many slightly different adsorption sites leading to broadening of the $\mathrm{CO}$ vibrational absorption band. Although not yet applied for Mo, DFT calculations can be used to calculate CO vibrational frequencies for $\mathrm{CO}$ adsorbed on proposed structures [39]. Comparing the experimental results with calculated values helps determine which structures are present on the catalyst.

Dynamic nuclear polarization surface enhanced NMR spectroscopy (DNP SENS) measurements of the ${ }^{13} \mathrm{C}$ chemical shift give a much enhanced signal and better resolution compared to normal ${ }^{13} \mathrm{C}$ NMR spectroscopy [40-45]. The samples to be investigated are impregnated with a solution containing a stable free radical (usually bi-nitroxides), which allows transfer of polarization from its unpaired electrons to surrounding protons from either the solvent or the sample. Through cross-polarization and spin diffusion this polarization is then transferred to the nuclei of interest, in this case ${ }^{13} \mathrm{C}[46]$. To allow for the polarization to be transferred from ${ }^{1} \mathrm{H}$ to ${ }^{13} \mathrm{C}$, the two nuclei need to be in close contact. This way information can be gained about the proximity of protons from the Brønsted acid site (BAS) to the Mo (oxy-)carbides. If the acidic protons are not close enough to the Mo (oxy-)carbides, the polarization can be transferred through the solvent, which is also able to diffuse into the pores of the zeolite.

Because the spin can diffuse via the solvent, the radical can in principle be further away from ${ }^{13} \mathrm{C}$. TEKPol does not fit inside of the pores of the zeolite, which is a fact that can be exploited to distinguish between species on the outer surface of the zeolite and inside the pores of the zeolite [47]. 
In the MDA process, three phases are distinguished: (i) the activation period in which Mo carburizes and reduces to its active phase on which methane can be transformed to the intermediates of the reaction, (ii) the induction period, in which the benzene production slowly reaches its maximum rate, and (iii) the reaction/deactivation period of the reaction [14]. Both phase (i) and (ii) need to be completed for the catalyst to reach full activity. The induction period was previously ascribed to a hydrocarbon pool formation [14], but it could also be due to a further transformation of the Mo active site.

As in previous studies by the authors, three different loadings of Mo are used in the current study to cover a broad range of possible configurations Mo can assume on the zeolite, $1 \mathrm{wt} . \%, 2 \mathrm{wt} . \%$ and 5 wt.\%. As reported by the some of the authors [14, 48, 49], on the 1 wt.\% catalyst Mo is mostly present as mono- and to a lesser extent dimeric species. For $2 \mathrm{wt} . \%$ already some bigger Mo nanoparticles are formed, while the $5 \mathrm{wt} . \%$ catalyst contains a lot of Mo nanoparticles on the outer surface of the zeolite. It was shown that initial methane conversion asymptotically levels off with Mo loading, but linearly depends on the amount carbon present at the active site after the activation [49]. This means that the mono- and dimeric species incorporate relatively more carbon than the Mo nanoparticles and are also more active.

The authors have used operando XAS on the same system studied in this work and were able to track the reduction of Mo to (oxy-)carbidic species [49]. It was speculated that most of the Mo is present as mono- or dimeric species even after on-stream activation, since only a low intensity for the Mo-Mo scattering path was observed in the FT-EXAFS [14]. Information about how many different sites exist, their nuclearity and structure could not be deduced. EPR measurements lead to the conclusion that only about $8 \mathrm{wt} . \%$ of all Mo is present as an EPR detectable species, the paramagnetic $\mathrm{Mo}^{5+}[14] .{ }^{13} \mathrm{C}$ MAS NMR was also used to understand the chemical interaction of carbidic carbon with Mo and therefore the structure of the active site [49]. Aside from the chemical shift itself, the anisotropy of the observed resonances can reveal the uniformity and nuclearity of the contribution. ${ }^{13} \mathrm{C}$ MAS NMR, however, yields low intensity for the carbon of the Mo (oxy-)carbidic structures, because of the low amount of carbon present.

As we reported, an active Mo site equivalent to the one forming under MDA conditions can also be produced using a pretreatment of the catalyst in carbon monoxide (CO). This pretreatment leads to a coke-free catalyst, which does not need further activation [49].

Herein, we used this technique to obtain active sites, freely accessible for probe molecules that can be examined by IR. CO IR spectroscopy is used to determine the oxidation state, nuclearity and uniformity of the Mo species after activation. The obtained experimental results were compared to theoretical results from DFT calculations. For this, mostly oxycarbidic structures were considered as we previously found that a considerable amount of oxygen remained at the active site during activation, accounting for an average O/Mo ratio of 1 , while an average $\mathrm{C} / \mathrm{Mo}$ ratio of 0.9 was found [49]. We however also considered $\mathrm{Mo}_{4} \mathrm{C}_{3}$ (structure 17, Figure S12) as a structure without oxygen to be able to draw a comparison with previous DFT calculations of the methane dehydroaromatization activity over Mox $\mathrm{C}_{y}$ structures $[19,20]$. The samples activated in $\mathrm{CO}$ are also investigated by ${ }^{13} \mathrm{C} N M R$ and DNP SENS.

The described techniques are not only used to understand which structures form during the activation period, but are also employed to better understand whether the induction period occurs due to a hydrocarbon pool build up or due to further transformation of the active site. Instead of using a continuous stream of methane, samples are prepared by a pulsed reaction technique where pulses of methane are injected into a continuous flow of carrier gas. This leads to a high time resolution and good quantification $[8,14,49]$.

\section{Experimental}

Mo was introduced to the ammonium form of a commercial ZSM- 5 zeolite (Südchemie) with $\mathrm{Si} / \mathrm{Al}=13$ or a silicalite- 1 zeolite (synthesis details below) through incipient wetness impregnation (IWI) dissolving appropriate amounts of ammonium heptamolybdate (AHM) in a volume of water needed to fill the pores of the zeolite powder $(210 \mu \mathrm{l} / \mathrm{g})$. The samples were dried overnight at $80^{\circ} \mathrm{C}$ and calcined at $550^{\circ} \mathrm{C}$ for $7 \mathrm{~h}$ using a heating rate of $2^{\circ} \mathrm{C} / \mathrm{min}$. Samples are denoted as $\boldsymbol{y} \mathbf{M o - x}$, where $\boldsymbol{y}$ denotes 
the wt.\% of Mo introduced and $\boldsymbol{x}$ the pre-treatment. Catalysts were prepared with 1, 2 and 5 wt.\% of Mo.

Silicalite-1 was synthesized mixing $25.6 \mathrm{~g}$ TPAOH with $30.0 \mathrm{~g}$ distilled water, after which 36.9 $\mathrm{g}$ TEOS was added dropwise to the solution. The obtained mixture is aged at room temperature overnight. Afterwards the mixture was transferred into autoclaves to perform further crystallization at $150 \stackrel{\circ}{\mathrm{C}}$ for 10 days. After cooling down, the product was collected by filtration and washing, and dried in air overnight. The dried product was calcined at $550^{\circ} \mathrm{C}$ for $5 \mathrm{~h}\left(2{ }^{\circ} \mathrm{C} / \mathrm{min}\right)$ to remove the template [50].

CO carburization was performed in a custom-made setup, where a $30 \mathrm{ml} / \mathrm{min}$ flow of $2.5 \% \mathrm{CO}$ in He was continuously fed to the reactor containing $300 \mathrm{mg}$ catalyst, that had been pelletized and sieved to 212 to $425 \mu \mathrm{m}$ particles. The reactor consists of a quartz tube with an inner diameter of 6 $\mathrm{mm}$. A heating rate of $10{ }^{\circ} \mathrm{C} / \mathrm{min}$ to $800^{\circ} \mathrm{C}$ (if not otherwise stated) was applied and the reactor was kept at the final temperature for $1 \mathrm{~h}$. Samples subjected to this treatment are denoted as yMo-CO. $\mathrm{H}_{2}$ treatment was performed in the same setup and under the same conditions as $\mathrm{CO}$ carburization, but with a $30 \mathrm{ml} / \mathrm{min}$ flow of $5 \% \mathrm{H}_{2}$ in $\mathrm{He}$.

$\mathrm{CH}_{4}$ pulsing experiments were performed in a custom made setup described previously [14]. A catalyst mass of $300 \mathrm{mg}$ was pelletized and sieved to 212 to $425 \mu \mathrm{m}$ particles and filled in a quartz tube with a $4 \mathrm{~mm}$ inner diameter. It was equipped with an injection loop in the feed line kept at atmospheric pressure, injecting $223 \mu \mathrm{mol}$ every $200 \mathrm{~s}$ into a $30 \mathrm{ml} / \mathrm{min}$ flow of He by switching a multiposition valve to the reactor. The catalyst bed was heated to $700 \stackrel{\circ}{\circ}$ under a $30 \mathrm{ml} / \mathrm{min}$ flow of He. Once the temperature was reached the first pulse was injected. Samples subjected to $\mathrm{CH}_{4}$ pulsing are denoted as $\mathbf{y M o - z} \mathbf{C H}_{4}$ where $\boldsymbol{z}$ stands for the number of pulses applied.

Fourier transformed infrared spectroscopy (FT-IR) of the vibrations of $\mathrm{CO}$ adsorbed on the catalyst was measured in a custom made stainless-steel cell with $\mathrm{CaF}_{2}$ windows that could be sealed airtight inside the glovebox. Spectra were measured with the addition of 128 scans in transmission mode using a Nicolet FT-IR spectrometer equipped with a cryogenic MCT detector. Samples were transferred from either the $\mathrm{CO}$ pre-treatment setup, the $\mathrm{CH}_{4}$ pulsing setup or the $\mathrm{H}_{2}$ pre-treatment setup to the glovebox without exposure to the ambient atmosphere. Pre-treated samples were pressed undiluted into pellets with $10 \mathrm{~mm}$ diameter inside the glovebox and loaded into the IR cell. The sealed cell was then transferred to the spectrometer evacuated and cooled to $-167{ }^{\circ} \mathrm{C}$ with liquid $\mathrm{N}_{2}$ before introducing $250 \mu \mathrm{l} \mathrm{CO}$ pulses. The pulsing sequence for $\mathrm{CO}$ consisted of 6 pulses keeping the injection loop at $100 \mathrm{mbar}, 3$ pulses at $200 \mathrm{mbar}$ and another 11 pulses at 1 bar. One sample with 2 wt.\% Mo loading was not reduced but instead dried at $450{ }^{\circ} \mathrm{C}$ in the infrared cell under dynamic vacuum for $16 \mathrm{~h}$ and denoted $\mathbf{2 M o}$. All spectra were normalized by the framework vibration intensity at $1876 \mathrm{~cm}^{-1}$.

Dynamic Nuclear Polarization surface enhanced NMR spectroscopy (DNP SENS) sample preparation: $3.65 \mathrm{mg}$ of the radical TEKPol was first dissolved in $20 \mu \mathrm{l}$ of 1,1,2,2-tetrachloroethylene (TCE) and then mixed well with about $20 \mathrm{mg}$ of the sample inside an Ar glovebox. The impregnated samples were packed into $3.2 \mathrm{~mm}$ o.d. sapphire rotors capped with a Teflon plug inside the glovebox and measured the same day. Spectra were acquired using $263 \mathrm{GHz} / 400 \mathrm{MHz}$ Avance III Bruker DNP solid-state NMR spectrometer $\left(v_{L}\left({ }^{13} \mathrm{C}\right)=100.6 \mathrm{MHz}\right)$ equipped with a $3.2 \mathrm{~mm}$ Bruker triple resonance low temperature magic angle spinning (LTMAS) probe. The experiments were performed at $\sim 100 \mathrm{~K}$ with a $263 \mathrm{GHz}$ gyrotron. The sweep coil of the main magnetic field was set for the microwave irradiation occurring at the ${ }^{1} \mathrm{H}$ positive enhancement maximum of the TEKPol biradical. The ${ }^{13} \mathrm{C}$ NMR experiments the acquisition parameters used are $20 \mathrm{~s}$ repetition delay to allow complete relaxation, a ${ }^{1} \mathrm{H} \pi / 2$ pulse length of $2.5 \mu$ s to afford $100 \mathrm{kHz}{ }^{1} \mathrm{H}$ decoupling using the SPINAL 64 decoupling method. A contact time between ${ }^{1} \mathrm{H}$ and ${ }^{13} \mathrm{C}$ was set to $8 \mathrm{~ms}$. 5,000-15,000 scans were performed, the MAS frequency varied between 8 and $10 \mathrm{kHz}$. All ${ }^{13} \mathrm{C}$ NMR spectra were referenced to adamantane with the higher frequency peak set to $38.48 \mathrm{ppm}$ with respect to TMS (0 ppm). DNP enhancements factors $\left(\varepsilon_{H}\right)$ of the TCE solvent were determined by comparing the integration of the resonance of interest for the spectra acquired with and without microwave irradiation. ${ }^{13} \mathrm{C}$ spin lattice relaxation times were measured using a saturation recovery experiment. Data are fitted using either a stretched- 
exponential (Formula 1) or a mono-exponential (Formula 2) with $A$ being the equilibrium signal intensity when microwave irradiation is used, $S(\tau)$ the integrated intensity at recycle delay time $\tau, \beta$ being the stretching parameter and $T_{1}^{*}$ the build-up time.

$$
\begin{aligned}
& S(\tau)=A\left[1-\exp \left(-\left(\frac{\tau}{T_{1}^{*}}\right)^{\beta}\right)\right] \\
& S(\tau)=A\left[1-\exp \left(-\frac{\tau}{T_{1}^{*}}\right)\right]
\end{aligned}
$$

For ${ }^{13} \mathrm{C} \mathrm{NMR}$ spectroscopy samples were prepared as described in section $\mathrm{CH}_{4}$ pulsing experiments using ${ }^{13} \mathrm{CH}_{4}$ and transferred from the setup to the glovebox without exposure to the atmosphere. A known amount of sample was filled into zirconia rotors inside the glovebox and tightly closed. 1D ${ }^{13} \mathrm{C}$ MAS NMR spectra were recorded on a Bruker AVANCE III spectrometer operating at resonance frequencies of $100 \mathrm{MHz}$, and using a conventional double resonance $4 \mathrm{~mm}$ CPMAS probe. The spinning frequency was set to $15 \mathrm{kHz}$. NMR chemical shifts are reported with respect to TMS as the external reference. Spectra were recorded by a spin echo pulse sequence (pulse length $3.4 \mu \mathrm{s}$ ) with four-phase alternation synchronized with the spinning rate for the MAS experiments. The interscan delay was set to $30 \mathrm{~s}$ to allow the complete relaxation, and 5,000-30,000 scans were performed. An apodization function (exponential) corresponding to a line broadening of $80 \mathrm{~Hz}$ was applied prior to the Fourier transformation.

Periodic DFT calculations were performed to determine the vibrational frequencies of $\mathrm{CO}$ adsorbed on Mo clusters in different speciation and oxidation state (between +2 and +6 ). For this purpose extra-framework $\left[\mathrm{Mo}_{x} \mathrm{O}_{y} \mathrm{C}_{z}\right]^{2+}(x=1,2$ or 4$)$ clusters were constructed in the ZSM-5 zeolite framework as counter-ion for two framework $\mathrm{Al}$ ions positioned in the six-membered ring located at the intersection of straight and zigzag channels, previously referred to as $\delta$-site (see Figure S11) [51]. This site was chosen as an open site allowing for anchoring of Mo species of different sizes and also leading to high symmetry of a pair of framework Al. Gao et al. calculated the Raman frequency for a monomeric oxide structure in this location and confirmed that it falls within the range observed experimentally [27]. The resulting ZSM-5 model had a Si/AI ratio of 47 . On the clusters one and two $\mathrm{CO}$ molecules were placed and their geometry optimized. All spin polarized DFT calculations were performed by using the Vienna Ab initio Simulation Package (VASP, version 5.3.5) [52-56]. The PBE functional based on the generalized gradient approximation was chosen to account for the exchangecorrelation energy [57]. A plane-wave basis set in combination with the projector augmented wave (PAW) method was used to describe the valence electrons and the valence-core interactions, respectively [58,59]. The kinetic energy cut-off of the plane wave basis set was set to $450 \mathrm{eV}$. A Gaussian smearing of the population of partial occupancies with a width of $0.05 \mathrm{eV}$ was used during iterative diagonalization of the Kohn-Sham Hamiltonian. Considering the large unit cell, Brillouin zonesampling was restricted to the $\Gamma$ point [60]. Geometry optimizations were assumed to have converged when forces on each atom were less than $0.04 \mathrm{eV} / \AA$. The Van der Waals (vdW) interactions were included by using Grimme's DFT-D3(BJ) method as implemented in VASP [61]. Geometry optimization was completed for all possible spin states for the given oxidation state which was followed by frequency analysis on the most stable spin state. Vibrational frequencies were calculated by determining the second derivatives of the Hessian matrix using the density functional perturbation theory as implemented in VASP 5.3.5. To decrease the computation costs only the CO molecules were considered in the analysis. The computed frequencies were corrected according to the following Formula 3.

$$
\frac{v_{\text {exp }}(C O)}{v_{\text {calc }}(C O)}=\frac{v_{\text {normalized }}\left(C O_{\text {ads }}\right)}{v_{\text {calc }}\left(C O_{\text {ads }}\right)}=1.009
$$

Formula 3

where $v_{\exp }(\mathrm{CO})$ is the experimentally measured frequency of the gas-phase $\mathrm{CO}\left(2143 \mathrm{~cm}^{-1}\right), v_{\text {calc }}(\mathrm{CO})$ is the calculated vibrational frequency $\left(2124 \mathrm{~cm}^{-1}\right), v_{\text {calc }}\left(\mathrm{CO}_{\text {ads }}\right)$ is the calculated $\mathrm{C}-\mathrm{O}$ vibrational frequency of the adsorbed $\mathrm{CO}$ molecule and $v_{\text {normalised }}\left(\mathrm{CO}_{\text {ads }}\right)$ is the corrected vibrational frequency of the adsorbed CO molecule. The difference between $v_{\text {calc }}(C O)$ and $v_{\exp }(C O)$ is about $19 \mathrm{~cm}^{-1}$ and provides an estimate of the expected error for the calculated frequencies.

Partial charges were calculated with the atoms in molecules (AIMS) method. The program was 
developed by the Henkelman Group [62-65].

The orthogonal MFI unit cell with lattice parameters of $a=20.241, b=20.015$ and $c=13.439 \AA$ as optimized by DFT with an all-silica MFI periodic model was used for all calculations. The optimized unit cell parameters agree well with experimental data for calcined ZSM-5.

The binuclear $\left[\mathrm{Mo}_{2} \mathrm{O}_{5}\right]^{2+}$ cluster at the same location of $\delta$-site was chosen to establish reaction pathways for reduction and carburization by methane and $\mathrm{CO}$. The kinetic energy cut-off of the plane wave basis set was set to $500 \mathrm{eV}$, and the geometries were assumed to have converged when forces on each atom were less than $0.05 \mathrm{eV} / \mathrm{A}$. All other parameters were the same as described above. All adsorption and desorption energies were corrected by taking enthalpy and entropy contributions of gas phase species into consideration. A typical reaction temperature of $700{ }^{\circ} \mathrm{C}$ and methane and $\mathrm{CO}$ partial pressures of $0.95 \mathrm{~atm}$ and $0.025 \mathrm{~atm}$ were used for thermodynamic corrections, respectively. For the products of $\mathrm{CO}, \mathrm{H}_{2}$ by methane carburization, $\mathrm{CO}_{2}$ by $\mathrm{CO}$ carburization, the partial pressures of $0.1 \mathrm{~atm}, 0.2 \mathrm{~atm}$, and $0.001 \mathrm{~atm}$ were used, respectively. It is expected that the partial pressure fluctuations in the reactor would have negligible influences on the thermodynamics.

\section{Results}

\subsection{CO IR}

Using a CO pretreatment the active phase of Mo was created avoiding any carbonaceous deposits, which surround the active site after activation under methane. The absence of those deposits allows probe molecules to absorb on the active site. CO vibrations were probed after adsorption on fresh samples as well as samples reduced in CO Figure 1 (see Figure S4 for full spectra). The CO activated sample shows several distinct vibrations (Figure b), while only the vibrations characteristic of the zeolite are observed on the fresh sample, $\mathbf{2 M o}$ (Figure 1a) namely $\mathrm{CO}$ adsorbed on Brønsted acid sites $\left(2173 \mathrm{~cm}^{-1}\right.$, BAS) with a shoulder at $2164 \mathrm{~cm}^{-1}$ which is assigned to Al-OH [66] or silanols [67] as well as a band at $2138 \mathrm{~cm}^{-1}$ characteristic of physisorbed $C O$ [68]. A slight decrease in acidity is observed on the $\mathrm{CO}$ treated sample as well, likely due to dehydration/dehydrogenation occurring at the high temperature of the activation [69-71]. This however is not accompanied by a change in morphology and extraction of Al. The ${ }^{27} \mathrm{Al}$ MAS spectra comparing the dehydrated as-synthesized samples to the samples carburized in $\mathrm{CO}$ show very similar features (Figure S8). The same vibrations of $\mathrm{CO}$ can be observed on a sample activated in methane confirming that similar Mo species are forming with both pre-treatments (Figure S4). The absorbances however are slightly lower, maybe due to some carbonaceous deposits formed during activation in methane blocking access to the active site. More information about the different Mo sites observed can be gained from deconvolution of the vibrational spectrum as shown in Figure 1c with spectra collected at low CO coverage on 5Mo-CO. The two pink bands $\left(2121\right.$ and $\left.2153 \mathrm{~cm}^{-1}\right)$ and the two turquoise bands $\left(2133\right.$ and $\left.2163 \mathrm{~cm}^{-1}\right)$, respectively, grow simultaneously with the same rate. This is demonstrated in Figure S6, which shows the intensities of each vibrational contribution plotted against the number of pulses of $\mathrm{CO}$ introduced to the sample. Because the intensity of the two turquoise and the two pink bands grow simultaneously, each of these pairs likely corresponds to two $\mathrm{CO}$ molecules adsorbed as dicarbonyls on the same Mo site. The two turquoise bands and the dark blue bands (Figure 1c) already appear at low pressures of $\mathrm{CO}$ (dark blue spectra in Figure 1b), while the two pink bands appear only after the turquoise and the dark blue bands do not grow any further. Around the same time the bands corresponding to BAS appear. The silanol bands are less acidic and only adsorb CO later on. Only after almost all other sites are saturated, the band for loosely physisorbed CO appear. 
a)

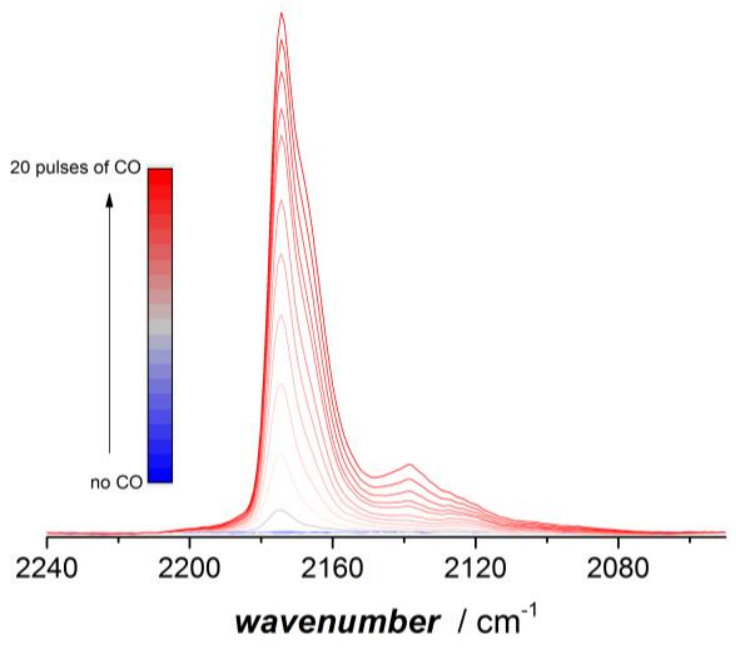

b)

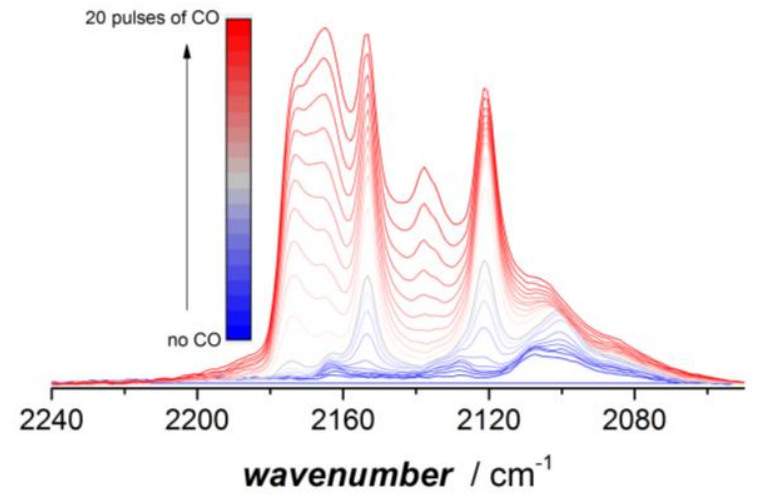

c) d)

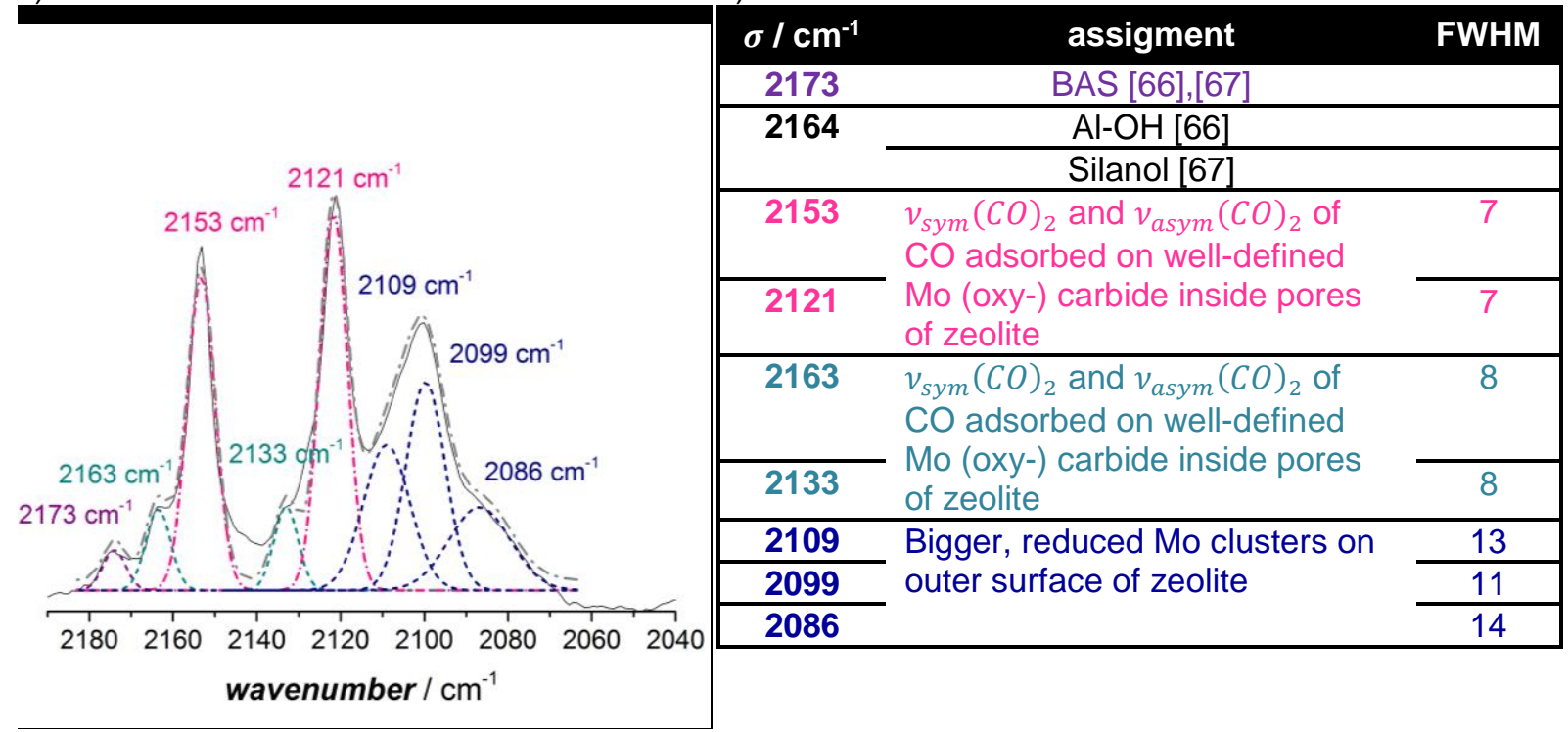

Figure 1. a) IR-spectra of the $\mathrm{CO}$ vibrations after consecutive pulsing of $\mathrm{CO}$ to $2 \mathrm{Mo}$. b) after consecutive pulsing of $\mathrm{CO}$ to $\mathbf{5 M o - C O}$. c) Gaussian deconvolution of the spectrum taken after introducing 9 pulses of $\mathrm{CO}$ to $5 \mathrm{Mo}-\mathbf{C O}$. A spectrum was taken after each pulse of $\mathrm{CO}$ sent to the evacuated IR cell kept at $-167^{\circ} \mathrm{C}$. A total of 20 pulses was sent to the cell in a sequence described in the experimental part. The pre-treated samples were transferred to the IR cell without exposure to the atmosphere. d) Summary of all observed vibrations with assignment, references and FWHM.

This is further supported by the fact that they are separated by $\Delta \sigma=33 \mathrm{~cm}^{-1}$, a separation distance for dicarbonyl absorbances observed elsewhere [72]. The four dicarbonyl bands are rather narrow with a full width at half maximum (FWHM) of 7 and $8 \mathrm{~cm}^{-1}$. Another broad absorbance is observed at around $2100 \mathrm{~cm}^{-1}$ and seems to comprise three rather broad contributions with a FWHM ranging between 11 and $14 \mathrm{~cm}^{-1}$. These broad vibrations around $2100 \mathrm{~cm}^{-1}$ are observed in higher intensity, the higher the loading of Mo. CO adsorption on $\mathbf{2 M o / s i l i c a l i t e - 1}$ treated in $\mathrm{CO}$ was also probed by IR (Figure S7), because the silicalite-1 support provides no Al sites for anchoring the Mo and should provide a good reference for Mo nanoparticles. Only two broad absorbances between 2080 and $2100 \mathrm{~cm}^{-1}$ are observed apart from the vibrations corresponding to the silicalite-1 support.

\subsection{DFT calculation of $\mathrm{CO}$ vibrations}

DFT calculations were performed to gain more insight into the nature of the Mo species giving rise to the CO vibrations observed experimentally. 18 different possible mono-, di- and tetrameric (oxy-)carbide structures were proposed and the vibrational frequencies of $\mathrm{CO}$ adsorbed on those structures calculated. Both the adsorption of one $\mathrm{CO}$ on one structure as well as two $\mathrm{CO}$ molecules on 
one structure was explored. When a second carbonyl is adsorbed, two new vibrations arise as the vibrations of the two $\mathrm{CO}$ molecules are coupled to a symmetric and an antisymmetric stretching vibration. This is the case both for monomeric and dimeric Mo-structures. When relating the wavenumber of the $\mathrm{CO}$ vibration and the nuclearity of the species no clear trend can be observed. Instead the wavenumber seems to increase with the partial charge of molybdenum (Figure 2 and Figure S9). Wavenumbers of both adsorbed single carbonyls (Figure S9) as well as dicarbonyls (Figure 2) follow a linear trend with the partial charge. The separation between the dicarbonyl vibrations $\Delta \sigma$ is inversely proportional to the partial charge for the monomers and dimers (Figure 2). The same trend can in principle be observed for the tetramers, but the calculations for the tetramers corresponding to structure 10 and 16 (Figure S12), yielded very high values of $\Delta \sigma$, which is due to the fact that the four Mo of the tetramer have a different electronic structure. The range of wavenumbers observed $\left(\sim 2060\right.$ to $\left.\sim 2170 \mathrm{~cm}^{-1}\right)$ corresponds to a partial charge between 1.5 and 2.4.

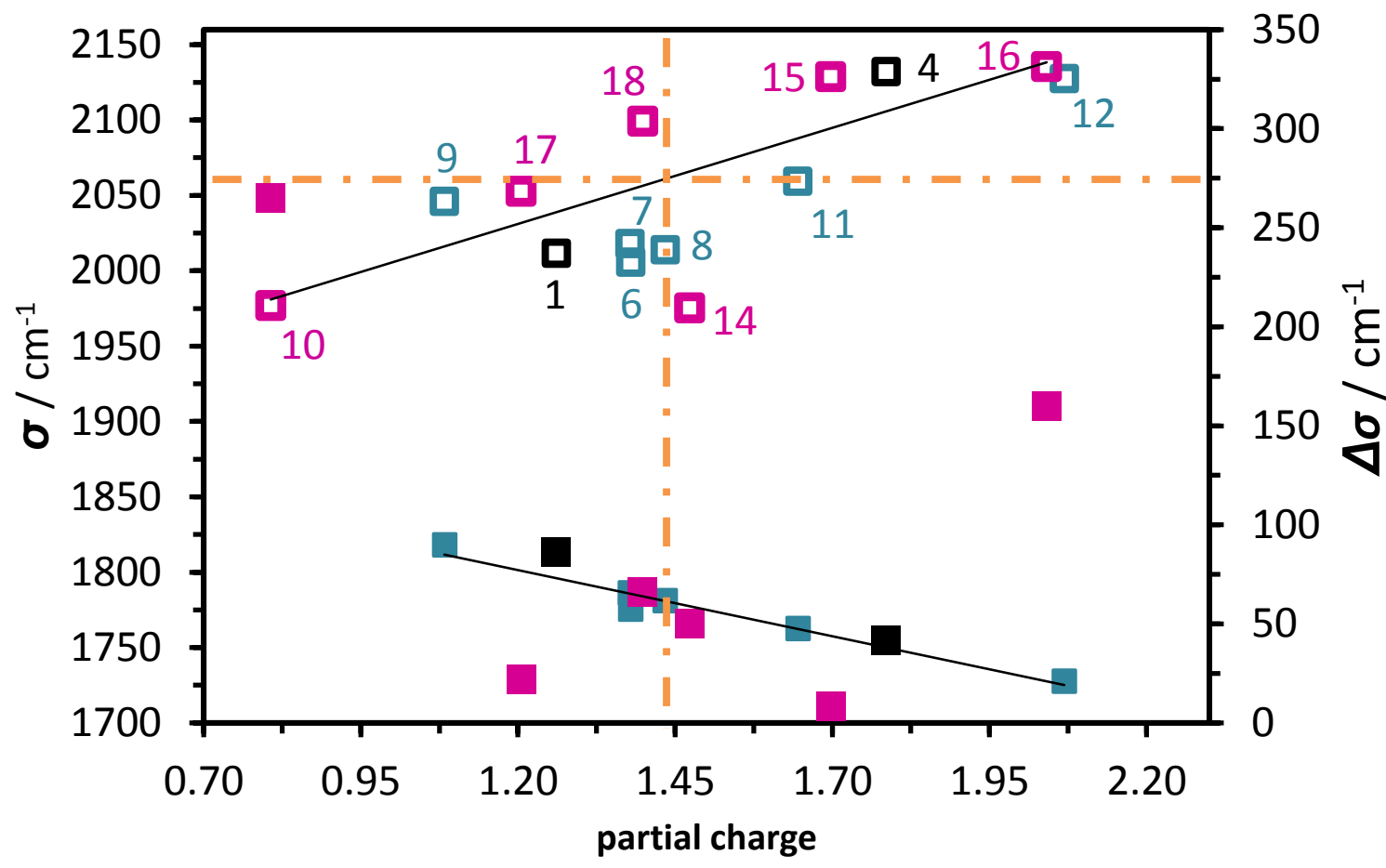

Figure 2. Vibrational wavenumbers of the symmetric stretching of the dicarbonyls (open symbols) and separation $\Delta \sigma$ between the two contributions (filled symbols) as calculated by DFT plotted against partial charge. Colors key: pink: tetramers, turquoise: dimers, black: monomers. The horizontal orange line indicates the lowest wavenumber observed experimentally, while the vertical line represents the lower limit regarding partial charge. Thus all points above and to the right of the orange lines could be possible candidates of Mo structures present on the investigated samples based on this analysis. Corresponding structures are shown in Figure S12.

Finally this information can be used to find the formal oxidation state corresponding to the experimentally observed wavenumbers, because the partial charge of molybdenum is proportional to the formal oxidation state (Figure S10). From this correlation, it can be concluded that Mo has a formal oxidation state of Mo between 4+ and 6+. For a given formal oxidation state however, the partial charge for structures containing carbon is generally lower than for structures without carbon. This is, because the formal oxidation state of carbon is -4 and for oxygen only -2 , while oxygen is much more electronegative, meaning that the partial charge remains almost the same when replacing oxygen by carbon in a given structure (compare structure 6 and 8 in Figure S12). This illustrates well that the partial charge is a better descriptor compared to formal oxidation state, when one wants to correlate the charge of a metal species with the vibrational frequency of $\mathrm{CO}$ adsorbed on that metal species. 


\section{3 ${ }^{13} \mathrm{C}$ MAS NMR}

${ }^{13} \mathrm{C}$ NMR spectra collected after sending several $233 \mu \mathrm{mol}$ pulses of ${ }^{13} \mathrm{CH}_{4}$ to 5 Mo during the induction period are presented in Figure $\mathbf{3 b}$ and $\mathbf{S 1 8}$. Figure $\mathbf{3 a}$ and Figure $\mathbf{S} 15$ show the MS readouts during pulsing. During the first 14 pulses of methane sent to the catalyst, no benzene formation is observed, marking the 'activation period'. After the activation of Mo is completed, benzene starts to be produced and the rate of formation slowly increases until it reaches its steady state value at around pulse 35 . This gradual increase represents the 'induction period' and was previously attributed to an accumulation of catalytically active polyaromatic coke that acts as a hydrocarbon pool [14]. The first ${ }^{13} \mathrm{C}$ MAS NMR spectrum was collected right before the onset of benzene production after Mo activation was completed (Figure 3b). The same three Mo (oxy-)carbide contributions as previously observed on the 5 Mo pretreated in $\mathrm{CO}$ [49] can be observed on this sample activated under MDA conditions. Two broader contributions at $360 \mathrm{ppm}$ and $306 \mathrm{ppm}$ were attributed to well-defined monoor dimeric Mo (oxy-)carbide species inside the pores of the zeolite and a third contribution at $270 \mathrm{ppm}$ to bigger $\mathrm{Mo}_{2} \mathrm{C}$ nanoparticles on the outer surface of the zeolite.

a)

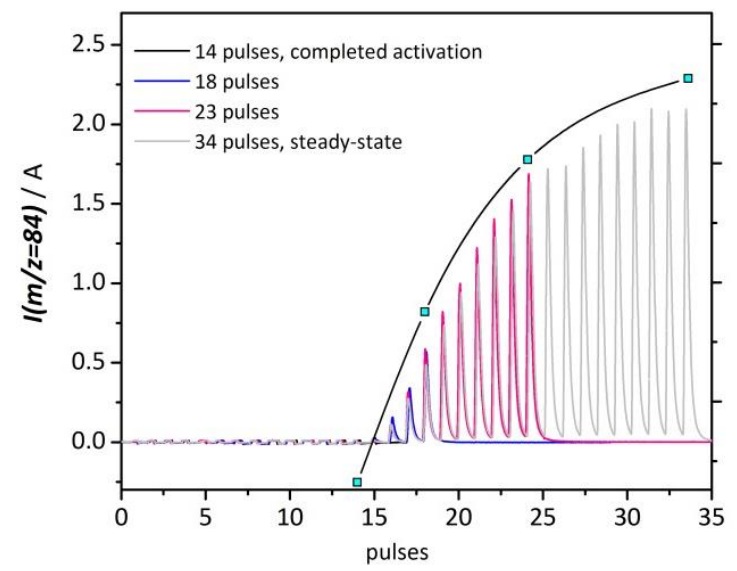

b)

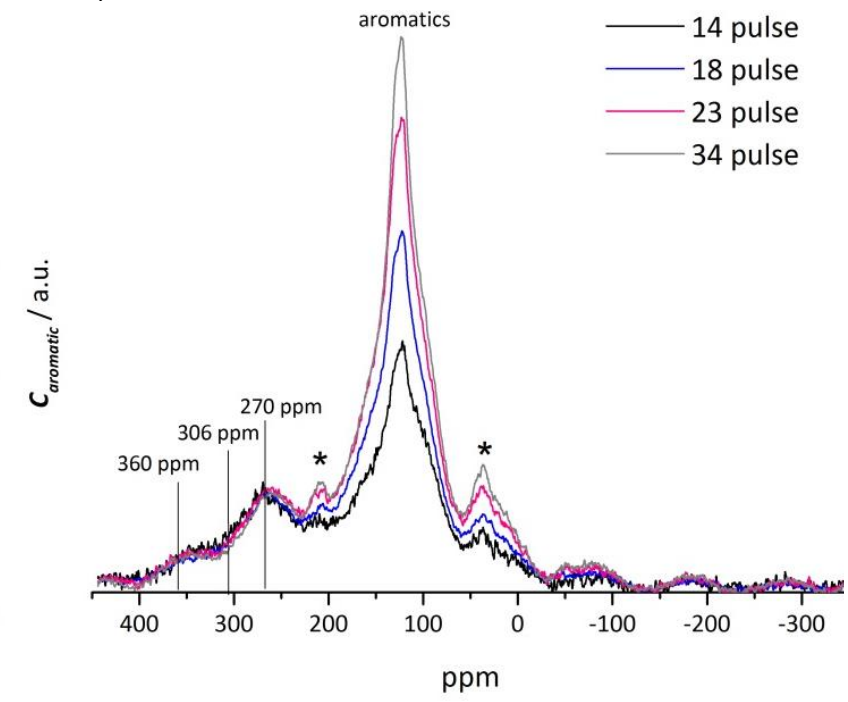

Figure 3. a) left axis: MS readout for $\mathrm{C}_{6} \mathrm{H}_{6}(\mathrm{~m} / \mathrm{z}=84)$ during consecutive pulsing of $233 \mu \mathrm{mol}$ of ${ }^{13} \mathrm{CH}_{4}$ at $700{ }^{\circ} \mathrm{C}$ into a continuous flow $30 \mathrm{ml} / \mathrm{min}$ He over $300 \mathrm{mg}$ of $5 \mathrm{Mo}$. Right axis: polyaromatic carbon content obtained from deconvolution of ${ }^{13} \mathrm{C}$ MAS NMR spectra (Figure S18) plotted in b). b) ${ }^{13} \mathrm{C}$ NMR spectra measured on the samples prepared by the pulsing experiments depicted in a). A fresh 5 Mo sample was subjected to 14, 18, 23 and 34 pulses sealed and transferred to NMR rotors without exposure to the atmosphere. Asterisks denote spinning sidebands.

In addition to the signatures of the Mo (oxy-)carbides, another resonance corresponding to polyaromatic carbon is observed at $121 \mathrm{ppm}$ [14, 73-77]. This polyaromatic carbon already forms while Mo is still being activated. After 3, 9 and 20 more pulses, the resonances corresponding to Mo (oxy-)carbides do not change further. Instead accumulation of more polyaromatic carbon on the catalyst is observed. The relative amount of polyaromatic carbon on the samples taken after an increasing number of $\mathrm{CH}_{4}$ pulses was determined by deconvolution (see Figure $\mathbf{S 1 8}$ for an example deconvolution of the spectra shown in Figure $3 \mathbf{b}$ ) of the ${ }^{13} \mathrm{C}$ NMR spectra and is plotted together with the MS readouts at $m / z=84$ in Figure 3a. Interestingly, polyaromatic carbon accumulates, mostly inside the pores of the catalyst [14], at the same rate as the benzene production goes up.

\subsection{DNP SENS}

DNP spectra shown in Figure 4 show that well-separated peaks can be resolved for Mo (oxy-)carbides, while these contributions shown in our previous publication [49] (reproduced in Figure $\mathbf{S 1 7}$ ) and in Figure $\mathbf{3 b}$ are rather broad and were only visible after collecting many scans. For the lowest loading of Mo, $\mathbf{1 M o}-{ }^{13} \mathrm{CO}$ two peaks can clearly be observed at 360 and $306 \mathrm{ppm}$, where with ${ }^{13} \mathrm{C}$ NMR only one broad resonance was observed in that region (Figure S17). These resonances are 
assigned to well-defined species inside the pores of the zeolite [49]. Very good enhancement of $\varepsilon H=90 \pm 4$ and $105 \pm 5$ were observed in proton experiments using TCE for the low loading Mo samples, $1 \mathrm{Mo}-{ }^{13} \mathrm{CO}$ and $2 \mathrm{Mo}-{ }^{13} \mathrm{CO}$, respectively (Figure S19). For the high loading, $5 \mathrm{Mo}-{ }^{13} \mathrm{CO}$ however no enhancement could be observed initially, instead the signal for the decomposed radical was observed (Figure S20) [45]. On this sample several bigger nanoparticles are present on the outer surface of the zeolite and therefore $\mathrm{Mo}$ is in direct contact with the radical, while for $\mathbf{1} \mathrm{Mo}^{13} \mathrm{CO}$ and $\mathbf{2} \mathrm{Mo}^{-13} \mathrm{CO}$, Mo is shielded from the radical inside the pores of the zeolite. TEKPol with $d_{\text {molecule }} \sim 2 \mathrm{~nm}$ is too big to penetrate the pores with $d_{\text {pore }} \sim 0.6 \mathrm{~nm}$ [45]. TEKPol can decompose when in direct contact with an organometallic complex immobilized on silica [45], so it is concluded that the bigger nanoparticles on the outer surface of $5 \mathbf{M o}^{-13} \mathbf{C O}$ fully decompose TEKPol.
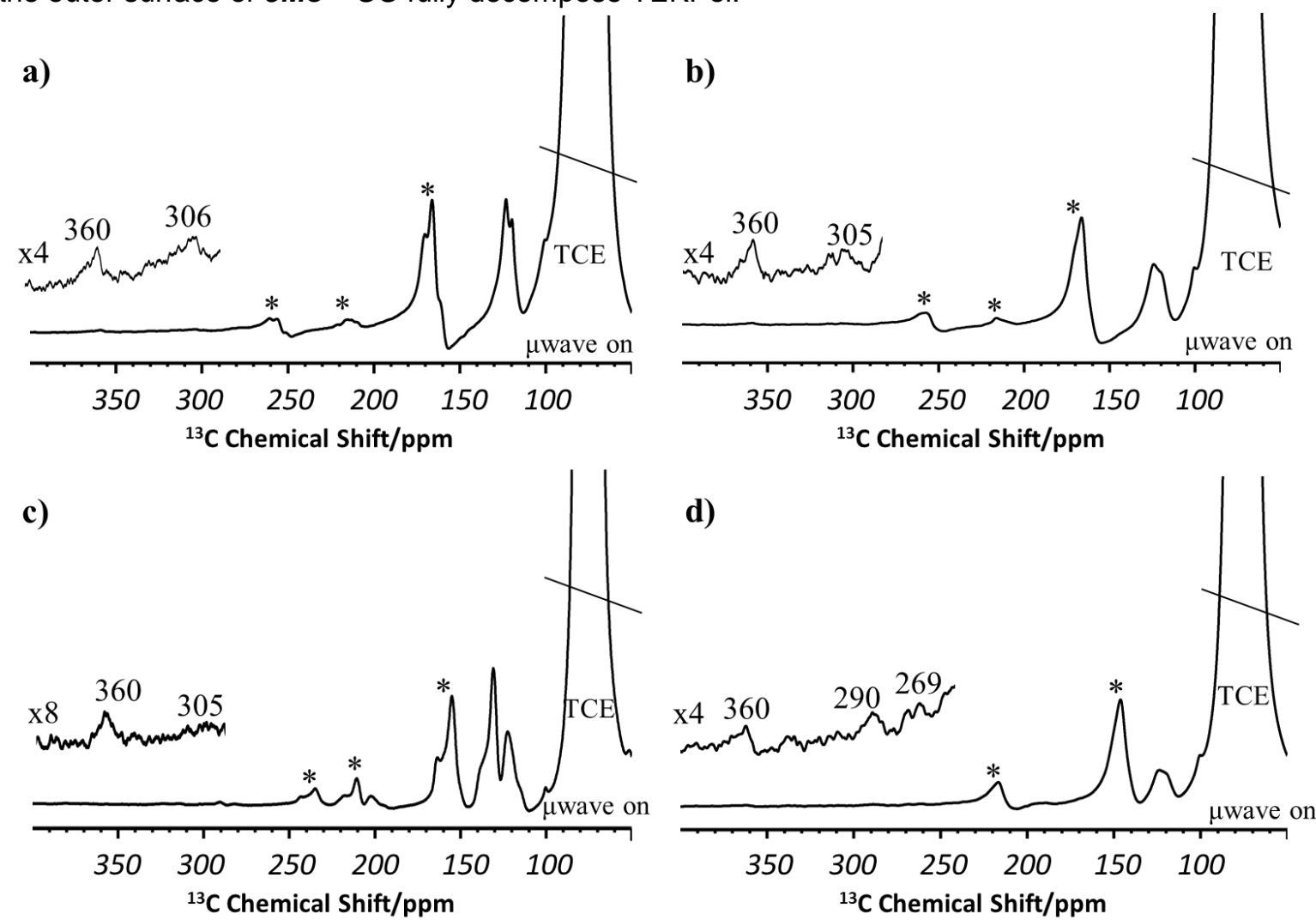

Figure 4. DNP SENS ${ }^{13} \mathrm{C}$ MAS NMR spectra of a) $1 \mathrm{Mo}^{13} \mathrm{CO}$ b) $2 \mathrm{Mo}^{13} \mathrm{CO}$ c) $5 \mathrm{Mo}^{13} \mathrm{CO}$ after a second impregnation with TEKPol d) $5 \mathrm{Mo-18}{ }^{13} \mathrm{CH}_{4}$. a) to c) were measured at a MAS frequency of $9 \mathrm{kHz}$, while d) was measured at $8 \mathrm{kHz}$. The measurement was performed at different rotation speeds to identify spinning side bands, which are indicated by the asterisks. $1 \mathbf{M o}^{13} \mathbf{C O}$ measured at $8 \mathrm{kHz}$ can be found in Figure $\mathbf{S 2 1}$ for comparison.

After impregnating the sample a second time with the radical solution an enhancement of $\varepsilon_{H}=32 \pm 3$ was observed for $5 \mathrm{Mo}^{-{ }^{13}} \mathrm{CO}$. It is important to note that the spectra measured after the second impregnation with TEKPol (Figure 4c) still did not show the resonance corresponding to $\mathrm{Mo}_{2} \mathrm{C}$ nanoparticles at 270 ppm observed in Figure 3, because the decomposed TEKPol that is still in close proximity to the $\mathrm{Mo}_{2} \mathrm{C}$ sites has a paramagnetic character and renders the carbon next to it NMR invisible.

When impregnating the sample $5 \mathrm{Mo}-18^{13} \mathrm{CH}_{4}$ carburized by 18 pulses of ${ }^{13} \mathrm{CH}_{4}$ (the same sample used for the ${ }^{13} \mathrm{C}$ NMR measurements shown in Figure 3 with the TEKPol solution) an enhancement of $\varepsilon_{H}=43 \pm 3$ can be observed immediately upon the first exposure to TEKPol (Figure S22) and only weak signals for degraded TEKPol are observed. At the same time Figure 4d shows that the contribution for bigger $\mathrm{Mo}_{2} \mathrm{C}$ nanoparticles at $269 \mathrm{ppm}$ can be observed. 


\section{Discussion}

The active sites of Mo/HZSM-5 form during an initial period of the MDA reaction coined 'activation period', where no desired products are formed yet and where coking is concurring together with the transformation of Mo to its active phase. A possible pathway for this carburization is presented together with thermodynamic analysis of the separate steps is presented in Figure S23. Both the pathway of carburization with $\mathrm{CO}$ as well as with $\mathrm{CH}_{4}$ is explored. Similar Mo species are forming on a catalyst treated in $\mathrm{CO}$ and one that was activated in methane confirmed by the fact that the same $\mathrm{CO}$ vibrations and the same ${ }^{13} \mathrm{C}$ NMR and DNP SENS resonances are observed for the two treatments.

While it has been proposed in literature that Mo forms (oxy-)carbidic species at reaction conditions and that some Mo stays anchored inside the pores of the zeolite while some Mo is present as bigger clusters and nanoparticles on the outer surface of the zeolite crystal, here we provide direct spectroscopic evidence showing distinct contributions that can be assigned to two different kinds of species inside the pores of the zeolite as well as the previously proposed nanoparticles on the outer surface of the zeolite. This is demonstrated using CO IR together with computational modeling as well as ${ }^{13} \mathrm{C}$ NMR and DNP SENS.

The vibrations of the $\mathrm{CO}$ probe molecule adsorbed on the activated samples are very sensitive to the electronic structure of Mo [38] and the FWHM of the observed vibrations can give information about the nuclearity of the adsorption site [36]. The various distinct $\mathrm{CO}$ vibrations observed on the pretreated Mo/HZSM-5 samples, allow us to distinguish between the different activated Mo species.

Direct assignment of the observed wavenumbers however, becomes very difficult, because relatively little infrared studies of $\mathrm{CO}$ adsorbed on Mo species are found in literature. Zaki et al. [78] provide a good summary of the literature of Mo supported on different oxides and also further investigate $\mathrm{CO}$ adsorption of reduced species at $77 \mathrm{~K}$. But, on the studied catalysts Mo is mostly present as nanoparticles, which are not comparable to the mono- and dimeric species reported in the current manuscript. In addition, the applied reducing treatments include $\mathrm{H}_{2}$ reduction and $\mathrm{CO}$ photo-reduction, but no carburizing treatment was employed. The $\mathrm{CO}$ absorbance wavenumbers observed after the $\mathrm{H}_{2}$-treatement (Figure S13) are very different from those observed for $\mathrm{CO}$ adsorbed on the carburized samples (Figure 1), which explains the mismatch between the wavenumbers observed by Zaki et al. and our results. Rasko et al. report CO IR recorded at RT for Mo nanoparticles carburized in a $\mathrm{CH}_{4} / \mathrm{H}_{2}$ mixture supported on silica [79], while Wu et al. provide a study of a similarly prepared catalyst supported on alumina [80]. But their observed vibrational frequencies match only match the wavenumbers for $\mathrm{CO}$ adsorbed on nanoparticles observed in this study. Spectra were also recorded at $\mathrm{RT}$ instead of at $77 \mathrm{~K}$ as in the current study. Chen et al. study $\mathrm{CO}$ and $\mathrm{CH}_{4}$ adsorption on $\mathrm{MoO}_{3} / \mathrm{HZSM}-5$ [81], but only find absorbance wavenumbers of $\mathrm{CO}$ adsorbed on the acid sites of the zeolite support, since $\mathrm{CO}$ does not adsorb on fully oxidic Mo. Table III in [72] shows that the separation of $v_{\text {sym }}(\mathrm{CO})_{2}$ and $v_{\text {asym }}(\mathrm{CO})_{2}$ for $\mathrm{Mo}^{4+}(\mathrm{CO})_{2}$ supported on $\mathrm{TiO}_{2}$ and $\mathrm{CeO}_{2}$ resembles what is observed in this study, but the $\mathrm{CO}$ absorbances are observed at lower wavenumbers. This could be, because the size of species studied by Williams et al. are much bigger than the species in the current study. It could also be due the large differences between the supports used. The observed wavenumbers seem to heavily depend on the pretreatment used to create reduced Mo. Williams et al. report the wavnumbers of $\mathrm{Mo}^{4+}(\mathrm{CO})$ between 2186 vs 2180 , but after sulfidation, the wavnumbers of $\mathrm{Mo}^{4+}(\mathrm{CO})$ are more similar to what is observed in our study. The lack of infrared studies on $\mathrm{CO}$ adsorbed on Mo and more specifically on molecular Mo and Mo species supported on zeolite highlights the importance of our work. Generally, little (theoretical) studies exist on CO IR of transition metal ions supported on zeolites.

The narrow FWHM of the dicarbonyl species is indicative for presence of two types of sites with very similar geometry, which only contain a few atoms, previously coined 'well-defined' species [36, 37]. Such small species are created inside the pores of the zeolite through anchoring to the Al of the framework. Previous studies [14, 48, 82] suggest that these are mono- and dimeric (oxy-)carbide species. The contributions of these well-defined species are not observed when the zeolite support 
used does not contain any framework $\mathrm{Al}$ for anchoring the Mo, as is the case for $\mathbf{2 M o / s i l i c a l i t e - 1}$ treated in CO (Figure S7) [49]. The two types of well-defined species are also observed with ${ }^{13} \mathrm{C}$ NMR and DNP SENS. While three contribution could already be seen by deconvolution of the ${ }^{13} \mathrm{C}$ NMR signal, the enhancement of the signal with DNP SENS enabled resolving three distinct and separated resonances.

A third species observed in all three characterization techniques is assigned to bigger Mo nanoparticles, because it leads to a broad contribution in the CO IR, typical for a site that allows the $\mathrm{CO}$ to adsorb on many slightly different locations of the nanoparticle with similar electronic structure. This species is observed in almost negligible amounts for low loadings of Mo (1 wt.\% and $2 \mathrm{wt} . \%)$ while it becomes a dominant species for $5 \mathrm{wt} . \%$ Mo loading. At the same time it leads to a rather narrow resonance in ${ }^{13} \mathrm{C}$ NMR, also indicative of nanoparticles. These nanoparticles were observed earlier by HR-TEM on an equivalent catalyst by Kosinov et al. [14]. I is suggested that these nanoparticles are mainly present on the outer surface of the zeolite, since a nanoparticle of Mo should not form inside the pores of the zeolite, because of size and because it is more likely to form coordinated structures in proximity to BAS. They don't directly exclude however that some smaller nanoparticles are located inside the pores of the zeolite.

In this regard, DNP SENS proved to be a very useful technique to clearly distinguish between (oxy-)carbidic Mo located on the outer surface of the zeolite and inside the pores. The DNP SENS measurements presented here confirm that the $\mathrm{Mo}_{2} \mathrm{C}$ nanoparticles are indeed only located at the outer surface of the zeolite particles. The biradical TEKPol decomposes, because it is in direct contact with the $\mathrm{Mo}_{2} \mathrm{C}$ nanoparticles and TEKPol is too large to penetrate the pores. Thus the nanoparticles have to be on the outer surface. The resonance corresponding to $\mathrm{Mo}_{2} \mathrm{C}$ also disappears, because TEKPol becomes paramagnetic when it decomposes and effectively makes carbon close by undetectable by NMR, which further confirms that the $\mathrm{Mo}_{2} \mathrm{C}$ nanoparticles must be located close to TEKPol and thus on the outer surface of the zeolite crystals. In line with this, for the sample activated with 18 pulses of methane, $\mathbf{5 M o - 1 8}{ }^{13} \mathbf{C H}_{4}$, the deposited aromatic carbon shields the bigger nanoparticles avoiding the decomposition of TEKPol and allowing for the resonance of $\mathrm{Mo}_{2} \mathrm{C}$ nanoparticles to be observed.

It was speculated that different kinds of Mo sites are present on Mo/HZSM-5 after activation, while it was not known how many different sites exist. With our findings, we were able to determine that (at least) three different (oxy-)carbidic species exist on Mo/HZSM-5 after activation. Knowledge about the exact number of different types of Mo sites provides a good starting point to assign different activity to those sites. Comparing DNP SENS measurements of samples prepared with $\mathrm{CH}_{4}$ and coke-free samples prepared with $\mathrm{CO}$ confirm that the aromatic carbon mostly is associated with bigger $\mathrm{Mo}_{2} \mathrm{C}$ nanoparticles on the outer surface of the zeolite, which is indication that these nanoparticles are the cause of deactivation through a kind of fouling.

In that case, only fully carburized nanoparticles of Mo are observed. This suggests that full carburization is only achieved of the bigger Mo nanoparticles, while it is very hard or impossible to fully carburize Mo when it is stabilized as mono- or dimeric species through the framework Al in the zeolite. This is also supported by the CO IR results, where the bigger Mo nanoparticles give rise to lower wavenumbers than the well-defined oxycarbidic species, meaning that the Mo nanoparticles are more reduced than the smaller, mono- or dimeric species.

As the mono- and dimeric species inside the pores of the zeolite seem to be most active for conversion of methane to valuable aromatics, we further elucidated the nature of these Mo sites using DFT calculations. Although for nanoparticles it was suggested that the wavenumber of $\mathrm{CO}$ generally decreases with higher Mo oxidation state, for well-defined, mono- or dimeric transition metal sites in zeolites and especially for Mo little information is available. We find a linear relationship between the observed CO vibrational wavenumber and the partial charge of Mo for well-defined sites. This partial 
charge can be translated to the formal Mo oxidation state (Figures 2, S9 and S10). For the experimentally observed $\mathrm{CO}$ vibrational wavenumbers it can be concluded that the $\mathrm{Mo}$ in these active sites has a formal oxidation state between $4+$ and $6+$. It is emphasized that simply reduced structures that do not contain any carbon can be excluded as active sites, because a sample reduced in $\mathrm{H}_{2}$ does not give rise to any of the vibrations observed on the samples treated in $\mathrm{CH}_{4}$ or $\mathrm{CO}$ (Figure S13). This $\mathrm{H}_{2}$ treated sample also exhibited lower benzene yields during MDA as was shown in our previous publication [49] and the EXAFS of that sample does not match with the spectra measured on the samples treated in $\mathrm{CO}$ or $\mathrm{CH}_{4}$ (Figure S14). Further, it should be noted that the structures highlighted in Figure 2 mostly contain only oxygen, but given that many (oxy-)carbidic structure calculated $\mathrm{CO}$ frequencies were close to the ones observed experimentally, we cannot exclude structures with similar partial charges that contain carbon. This especially in comparison to the ${ }^{13} \mathrm{C}$ NMR results and what has been proposed previously [9, 23, 24, 27, 83-85]. Furthermore, only a limited number of structures in only one location inside the zeolite framework could be considered here. The choice of structures was, however, sufficient to achieve our goal of determining a formal Mo oxidation state, but we cannot claim to have exhausted all configurational possibilities.

With more information about the exact nature of the active site after completion of the activation at hand, we wanted to investigate the impact of Mo speciation on the induction period occurring right after completion of the activation period. During this period benzene formation slowly increases to its maximum. The species observed with ${ }^{13} \mathrm{C}$ MAS NMR did not transform further during this period, so no further evolution and activation of the Mo sites takes place in the induction period. Instead the build-up of (poly-)aromatic carbon on the sample follows the same trend as the increase in benzene formation rate (Figure 3), suggesting that the build-up of a hydrocarbon pool $[14,86]$ is necessary for the catalyst to achieve maximum activity, while not leading to deactivation yet.

It has been speculated that Mo agglomerates at reaction conditions [27], our results however suggest that this agglomeration occurs later on in the process after the induction period. Figure 3 clearly indicates that no significant agglomeration occurs during the induction period, since the resonances corresponding to Mo (oxy-)carbide do not transform further during induction. This is also supported by $\mathrm{CO} I R$. There is no change in wavenumber of the $\mathrm{CO}$ vibrations for a sample that has seen 5 or 10 pulses of $\mathrm{CH}_{4}$ (Figure S16). The agglomeration of Mo might even be the cause of deactivation. The fact that the nanoparticles seem to be cause for deactivation is supported by our DNP SENS measurements, where we find that the aromatic carbon surrounds the bigger $\mathrm{Mo}_{2} \mathrm{C}$ nanoparticles (fouling) on the outer surface of the zeolite. This is concluded, because no TEKPol decomposition is observed on a sample containing aromatic carbon.

Although, we were able to distinguish between different Mo species present on the catalyst, it remains very difficult to assess whether one particular species is more active than another species. In a previous publication we demonstrated that the activity of the catalyst does not linearly increase with the Mo amount, but starts to levels off after $2 \mathrm{wt} . \%$. Instead activity linearly increases with the amount of carbon present at the active site after the activation period [49]. We had also found that the C/Mo ratio is higher for oxycarbidic Mo species anchored to the zeolite framework than for $\mathrm{Mo}_{2} \mathrm{C}$ nanoparticles. These two results together suggest that the oxycarbidic Mo species are more active than the $\mathrm{Mo}_{2} \mathrm{C}$ nanoparticles on the outer surface of the zeolite. In addition, oxycarbidic species are definitely active to initiate the hydrocarbon pool and to produce the final products benzene and naphthalene. The two catalysts with low loadings of Mo (1 and 2 wt.\%) were shown not to contain any fully carbidic species (Figure S17) and yet benzene and naphthalene is easily produced on those catalysts (Figure S2-3).

\section{Conclusions}

A quasi-in situ strategy is presented to directly probe the different types of Mo sites on the methane dehydroaromatization catalyst, Mo/HZSM-5, after activation. CO IR, ${ }^{13} \mathrm{C}$ NMR as well as DNP SENS combined with theory were used to find the nuclearity, charge and stoichiometry of the three different types of Mo sites observed. A coke-free active site was obtained using a $\mathrm{CO}$ pretreatment leading to 
very clear spectra. We provide direct spectroscopic evidence showing distinct contributions that can be assigned to two different kinds of species inside the pores of the zeolite as well as nanoparticles on the outer surface of the zeolite. The latter contribute to the deactivation of the catalyst by coke deposition.

For the observed Mo species an oxidation state between 3+ and 6+ was determined. The (oxy-)carbidic Mo species do not transform further during the induction period, but instead the build-up of a hydrocarbon pool is necessary for the catalyst to achieve maximum activity.

\section{Acknowledgements}

Financial support from the Sabic-NWO CATC1CHEM CHIPP project is gratefully acknowledged. Thanks go to Dr. Christoph Dittrich (SABIC), Dr. Frank Mostert (SABIC) and Dr. T. Alexander Nijhuis (SABIC) for helpful discussion. G. Li acknowledges financial support from The Netherlands Organization for Scientific Research (NWO) for her personal VENI grant (no. 016. Veni.172.034) and NWO-Surf SARA for providing access to supercomputer resources. The FAME-UHD project is financially supported by the French "grand emprunt" EquipEx (EcoX, ANR-10-EQPX-27-01), the CEACNRS CRG consortium and the INSU CNRS institute.

\section{References}

[1] M. Bender, Global Aromatics Supply - Today and Tomorrow, in: New Technologies and Alternative Feedstocks in Petrochemistry and Refining DGMK Conference, Dresden, Germany, 2013.

[2] N.E.T. Laboratory, An introduction to the science and energy potential of a unique resource, in: U.D.o. Energy (Ed.), US Department of Energy, US, 2011.

[3] O. Bragin, T. Vasina, Y.I. Isakov, B. Nefedov, A. Preobrazhenskii, N. Palishkina, K.M. Minachev, Catalytic aromatization of methane and ethane, Russ Chem Bull, 31 (1982) 847-847.

[4] L. Wang, L. Tao, M. Xie, G. Xu, J. Huang, Y. Xu, Dehydrogenation and aromatization of methane under non-oxidizing conditions, Catal Lett, 21 (1993) 35-41.

[5] C. Copéret, M. Chabanas, R. Petroff Saint-Arroman, J.-M. Basset, Homogeneous and Heterogeneous Catalysis: Bridging the Gap through Surface Organometallic Chemistry, Angewandte Chemie International Edition, 42 (2003) 156-181.

[6] M. Nachtegaal, U. Hartfelder, J.A. van Bokhoven, From Spectator Species to Active Site Using Xray Absorption and Emission Spectroscopy Under Realistic Conditions, in: J. Frenken, I. Groot (Eds.) Operando Research in Heterogeneous Catalysis, Springer International Publishing, Cham, 2017, pp. 89-110.

[7] I. Vollmer, I. Yarulina, F. Kapteijn, J. Gascon, Progress in Developing a Structure-Activity Relationship for the Direct Aromatization of Methane, ChemCatChem, (2019).

[8] H. Jiang, L. Wang, W. Cui, Y. Xu, Study on the induction period of methane aromatization over Mo/HZSM-5: partial reduction of Mo species and formation of carbonaceous deposit, Catal Lett, 57 (1999) 95-102.

[9] I. Lezcano-González, R. Oord, M. Rovezzi, P. Glatzel, S.W. Botchway, B.M. Weckhuysen, A.M. Beale, Molybdenum Speciation and its Impact on Catalytic Activity during Methane Dehydroaromatization in Zeolite ZSM- 5 as Revealed by Operando X-Ray Methods, Angewandte Chemie International Edition, 55 (2016) 5215-5219.

[10] F. Solymosi, A. Szöke, J. Cserényi, Conversion of methane to benzene over Mo2C and Mo2C/ZSM-5 catalysts, Catal Lett, 39 (1996) 157-161.

[11] D. Wang, J. Lunsford, M. Rosynek, Catalytic conversion of methane to benzene over Mo/ZSM-5, Top Catal, 3 (1996) 289-297.

[12] S. Liu, L. Wang, R. Ohnishi, M. Lchikawa, Bifunctional catalysis of Mo/HZSM-5 in the dehydroaromatization of methane with $\mathrm{CO} / \mathrm{CO} 2$ to benzene and naphthalene, Kinetics and catalysis, 41 (2000) 132-144.

[13] W. Ding, S. Li, G. D Meitzner, E. Iglesia, Methane conversion to aromatics on Mo/H-ZSM5: structure of molybdenum species in working catalysts, The Journal of Physical Chemistry B, 105 (2001) 506-513.

[14] N. Kosinov, A.S.G. Wijpkema, E. Uslamin, R. Rohling, F.J.A.G. Coumans, B. Mezari, A. Parastaev, A.S. Poryvaev, M.V. Fedin, E.A. Pidko, E.J.M. Hensen, Confined Carbon Mediating Dehydroaromatization of Methane over Mo/ZSM-5, Angewandte Chemie, 57 (2018) 1016-1020. [15] B.M. Weckhuysen, M.P. Rosynek, J.H. Lunsford, Characterization of surface carbon formed during the conversion of methane to benzene over Mo/H-ZSM-5 catalysts, Catal Lett, 52 (1998) 31-36. 
[16] F. Solymosi, A. Erdöhelyi, A. Szöke, Dehydrogenation of methane on supported molybdenum oxides. Formation of benzene from methane, Catal Lett, 32 (1995) 43-53.

[17] Y. Xu, L. Lin, Recent advances in methane dehydro-aromatization over transition metal ionmodified zeolite catalysts under non-oxidative conditions, Applied Catalysis A: General, 188 (1999) 5367.

[18] H. Liu, W. Shen, X. Bao, Y. Xu, Identification of Mo active species for methane dehydroaromatization over Mo/HZSM-5 catalysts in the absence of oxygen: $1 \mathrm{H}$ MAS NMR and EPR investigations, Journal of Molecular Catalysis A: Chemical, 244 (2006) 229-236.

[19] T.S. Khan, S. Balyan, S. Mishra, K.K. Pant, M.A. Haider, Mechanistic Insights into the Activity of Mo-Carbide Clusters for Methane Dehydrogenation and Carbon-Carbon Coupling Reactions To Form Ethylene in Methane Dehydroaromatization, The Journal of Physical Chemistry C, 122 (2018) 1175411764

[20] J. Gao, Y. Zheng, G.B. Fitzgerald, J. de Joannis, Y. Tang, I.E. Wachs, S.G. Podkolzin, Structure of Mo2Cx and Mo4Cx Molybdenum Carbide Nanoparticles and Their Anchoring Sites on ZSM-5 Zeolites, The Journal of Physical Chemistry C, 118 (2014) 4670-4679.

[21] R.O. Savinelli, S.L. Scott, Wavelet transform EXAFS analysis of mono- and dimolybdate model compounds and a Mo/HZSM-5 dehydroaromatization catalyst, Physical Chemistry Chemical Physics, 12 (2010) 5660-5667.

[22] M. Agote-Arán, A. Kroner, H. Islam, W. Slawinski, D. Wragg, I. Lezcano-Gonzalez, A.M. Beale, Determination of Molybdenum Species Evolution during Non-Oxidative Dehydroaromatization of Methane and its Implications for Catalytic Performance, ChemCatChem, 0.

[23] H. Zheng, D. Ma, X. Bao, J.Z. Hu, J.H. Kwak, Y. Wang, C.H.F. Peden, Direct Observation of the Active Center for Methane Dehydroaromatization Using an Ultrahigh Field 95Mo NMR Spectroscopy, Journal of the American Chemical Society, 130 (2008) 3722-3723.

[24] J.Z. Hu, J.H. Kwak, Y. Wang, C.H.F. Peden, H. Zheng, D. Ma, X. Bao, Studies of the Active Sites for Methane Dehydroaromatization Using Ultrahigh-Field Solid-State 95Mo NMR Spectroscopy, The Journal of Physical Chemistry C, 113 (2009) 2936-2942.

[25] D. Ma, W. Zhang, Y. Shu, X. Liu, Y. Xu, X. Bao, MAS NMR, ESR and TPD studies of Mo/HZSM-5 catalysts: evidence for the migration of molybdenum species into the zeolitic channels, Catal Lett, 66 (2000) 155-160.

[26] D. Ma, Y. Shu, X. Bao, Y. Xu, Methane Dehydro-aromatization under Nonoxidative Conditions over Mo/HZSM-5 Catalysts: EPR Study of the Mo Species on/in the HZSM-5 Zeolite, Journal of Catalysis, 189 (2000) 314-325.

[27] J. Gao, Y. Zheng, J.-M. Jehng, Y. Tang, I.E. Wachs, S.G. Podkolzin, Identification of molybdenum oxide nanostructures on zeolites for natural gas conversion, Science, 348 (2015) 686-690.

[28] J.C. Fierro-Gonzalez, S. Kuba, Y. Hao, B.C. Gates, Oxide- and Zeolite-Supported Molecular Metal Complexes and Clusters: Physical Characterization and Determination of Structure, Bonding, and Metal Oxidation State, The Journal of Physical Chemistry B, 110 (2006) 13326-13351.

[29] S. Bordiga, C. Lamberti, F. Bonino, A. Travert, F. Thibault-Starzyk, Probing zeolites by vibrational spectroscopies, Chemical Society Reviews, 44 (2015) 7262-7341.

[30] C. Lamberti, A. Zecchina, E. Groppo, S. Bordiga, Probing the surfaces of heterogeneous catalysts by in situ IR spectroscopy, Chemical Society Reviews, 39 (2010) 4951-5001.

[31] A. Zecchina, F. Geobaldo, C. Lamberti, S. Bordiga, G. Turnes Palomino, C. Otero Areán, Infrared studies of the interaction of carbon monoxide and dinitrogen with ferrisilicate MFI-type zeolites, Catal Lett, 42 (1996) 25-33.

[32] K.I. Hadjiivanov, Identification of Neutral and Charged $\mathrm{N} x \mathrm{O}$ y Surface Species by IR Spectroscopy, Catalysis Reviews, 42 (2000) 71-144.

[33] K.I. Hadjiivanov, G.N. Vayssilov, Characterization of oxide surfaces and zeolites by carbon monoxide as an IR probe molecule, in: Advances in Catalysis, Academic Press, 2002, pp. 307-511.

[34] E.V. Fadeeva, O.P. Tkachenko, A.V. Kucherov, A.P. Barkova, M.N. Mikhailov, A.M. Kuli-zade, M.M. Akhmedov, L.M. Kustova, Investigation of the molybdenum state in the Mo(4\%)/HZSM-5 catalyst for methane aromatization, Russ Chem Bull, 61 (2012) 2230-2235.

[35] G. Doyen, G. Ertl, Theory of carbon monoxide chemisorption on transition metals, Surface Science, 43 (1974) 197-229.

[36] R.J. Lobo-Lapidus, B.C. Gates, Supported Rhenium Complexes: Almost Uniform Rhenium Tricarbonyls Synthesized from CH3Re(CO)5 and HY Zeolite, Langmuir, 26 (2010) 16368-16374. [37] J.F. Goellner, B.C. Gates, G.N. Vayssilov, N. Rösch, Structure and Bonding of a Site-Isolated Transition Metal Complex: Rhodium Dicarbonyl in Highly Dealuminated Zeolite Y, Journal of the American Chemical Society, 122 (2000) 8056-8066. 
[38] J.B. Peri, Computerized infrared studies of molybdenum/alumina and molybdenum/silica catalysts, The Journal of Physical Chemistry, 86 (1982) 1615-1622.

[39] C.O. Areán, M.R. Delgado, K. Frolich, R. Bulánek, A. Pulido, G.F. Bibiloni, P. Nachtigall, Computational and Fourier Transform Infrared Spectroscopic Studies on Carbon Monoxide Adsorption on the Zeolites Na-ZSM-5 and K-ZSM-5: Evidence of Dual-Cation Sites, The Journal of Physical Chemistry C, 112 (2008) 4658-4666.

[40] B. Hamzaoui, A. Bendjeriou-Sedjerari, E. Pump, E. Abou-Hamad, R. Sougrat, A. Gurinov, K.-W. Huang, D. Gajan, A. Lesage, L. Emsley, J.-M. Basset, Atomic-level organization of vicinal acid-base pairs through the chemisorption of aniline and derivatives onto mesoporous SBA15, Chemical Science, 7 (2016) 6099-6105.

[41] T. Kobayashi, F.A. Perras, I.I. Slowing, A.D. Sadow, M. Pruski, Dynamic Nuclear Polarization Solid-State NMR in Heterogeneous Catalysis Research, ACS Catalysis, 5 (2015) 7055-7062.

[42] D. Lee, H. Takahashi, A.S.L. Thankamony, J.-P. Dacquin, M. Bardet, O. Lafon, G.D. Paëpe, Enhanced Solid-State NMR Correlation Spectroscopy of Quadrupolar Nuclei Using Dynamic Nuclear Polarization, Journal of the American Chemical Society, 134 (2012) 18491-18494.

[43] M. Lelli, D. Gajan, A. Lesage, M.A. Caporini, V. Vitzthum, P. Miéville, F. Héroguel, F. Rascón, A. Roussey, C. Thieuleux, M. Boualleg, L. Veyre, G. Bodenhausen, C. Coperet, L. Emsley, Fast Characterization of Functionalized Silica Materials by Silicon-29 Surface-Enhanced NMR Spectroscopy Using Dynamic Nuclear Polarization, Journal of the American Chemical Society, 133 (2011) 2104-2107.

[44] K. Märker, M. Pingret, J.-M. Mouesca, D. Gasparutto, S. Hediger, G. De Paëpe, A New Tool for NMR Crystallography: Complete 13C/15N Assignment of Organic Molecules at Natural Isotopic Abundance Using DNP-Enhanced Solid-State NMR, Journal of the American Chemical Society, 137 (2015) 13796-13799.

[45] E. Pump, J. Viger-Gravel, E. Abou-Hamad, M.K. Samantaray, B. Hamzaoui, A. Gurinov, D.H. Anjum, D. Gajan, A. Lesage, A. Bendjeriou-Sedjerari, L. Emsley, J.-M. Basset, Reactive surface organometallic complexes observed using dynamic nuclear polarization surface enhanced NMR spectroscopy, Chemical Science, 8 (2017) 284-290.

[46] M. Giulia, D. Myriam, Z. Fabio, T. Pierre, V. Stéphane, Quantitative Structural Constraints for Organic Powders at Natural Isotopic Abundance Using Dynamic Nuclear Polarization Solid-State NMR Spectroscopy, Angewandte Chemie International Edition, 54 (2015) 6028-6031.

[47] D. Mance, J. van der Zwan, M.E.Z. Velthoen, F. Meirer, B.M. Weckhuysen, M. Baldus, E.T.C. Vogt, A DNP-supported solid-state NMR study of carbon species in fluid catalytic cracking catalysts, Chemical Communications, 53 (2017) 3933-3936.

[48] N. Kosinov, F.J. Coumans, G. Li, E. Uslamin, B. Mezari, A.S. Wijpkema, E.A. Pidko, E.J. Hensen, Stable Mo/HZSM-5 methane dehydroaromatization catalysts optimized for high-temperature calcination-regeneration, Journal of Catalysis, 346 (2017) 125-133.

[49] I. Vollmer, B. van der Linden, S. Ould-Chikh, A. Aguilar-Tapia, I. Yarulina, E. Abou-Hamad, Y.G. Sneider, A.I. Olivos Suarez, J.-L. Hazemann, F. Kapteijn, J. Gascon, On the dynamic nature of Mo sites for methane dehydroaromatization, Chemical Science, 9 (2018) 4801-4807.

[50] N. Kosinov, V.G.P. Sripathi, E.J.M. Hensen, Improving separation performance of high-silica zeolite membranes by surface modification with triethoxyfluorosilane, Microporous and Mesoporous Materials, 194 (2014) 24-30.

[51] G. Li, E.A. Pidko, R.A. van Santen, C. Li, E.J.M. Hensen, Stability of Extraframework IronContaining Complexes in ZSM-5 Zeolite, The Journal of Physical Chemistry C, 117 (2013) 413-426.

[52] G. Kresse, J. Hafner, Ab initio molecular dynamics for liquid metals, Physical Review B, 47 (1993) 558-561.

[53] G.K.a.J. Hafner, Phys. Rev. B, 49 (1994) 14251-14269.

[54] G.K.a.J. Furthmüller, Phys. Rev. B Condens. Matter Mater. Phys, 54 (1996) 11169-11186.

[55] G. Kresse, J. Furthmüller, Efficient iterative schemes for ab initio total-energy calculations using a plane-wave basis set, Physical Review B, 54 (1996) 11169-11186.

[56] G. Kresse, J. Furthmüller, Efficiency of ab-initio total energy calculations for metals and semiconductors using a plane-wave basis set, Computational Materials Science, 6 (1996) 15-50.

[57] J.P. Perdew, K. Burke, M. Ernzerhof, Generalized Gradient Approximation Made Simple, Physical Review Letters, 77 (1996) 3865-3868.

[58] P.E. Blöchl, Projector augmented-wave method, Physical Review B, 50 (1994) 17953-17979.

[59] G. Kresse, D. Joubert, From ultrasoft pseudopotentials to the projector augmented-wave method, Physical Review B, 59 (1999) 1758-1775.

[60] H.J. Monkhorst, J.D. Pack, Special points for Brillouin-zone integrations, Physical Review B, 13 (1976) 5188-5192. 
[61] S. Grimme, S. Grimme, J. Antony, S. Ehrlich, and H. Krieg, A consistent and accurate ab initio parametrization of density functional dispersion correction (DFT-D) for the 94 elements H-Pu, J. Chem. Phys. 132, 154104 (2010), J. Chem. Phys., 132 (2010) 154104.

[62] W. Tang, E. Sanville, G. Henkelman, A grid-based Bader analysis algorithm without lattice bias, Journal of Physics: Condensed Matter, 21 (2009) 084204.

[63] S. Edward, K.S. D., S. Roger, H. Graeme, Improved grid-based algorithm for Bader charge allocation, Journal of Computational Chemistry, 28 (2007) 899-908.

[64] G. Henkelman, A. Arnaldsson, H. Jónsson, A fast and robust algorithm for Bader decomposition of charge density, Computational Materials Science, 36 (2006) 354-360.

[65] M. Yu, D.R. Trinkle, Accurate and efficient algorithm for Bader charge integration, The Journal of Chemical Physics, 134 (2011) 064111.

[66] K. Chakarova, K. Hadjiivanov, Problems in the IR measuring the acidity of zeolite bridging hydroxyls by low-temperature CO adsorption, Chemical Communications, 47 (2011) 1878-1880.

[67] M.S. Holm, S. Svelle, F. Joensen, P. Beato, C.H. Christensen, S. Bordiga, M. Bjørgen, Assessing the acid properties of desilicated ZSM- 5 by FTIR using $\mathrm{CO}$ and 2,4,6-trimethylpyridine (collidine) as molecular probes, Applied Catalysis A: General, 356 (2009) 23-30.

[68] I. Yarulina, J. Goetze, C. Gucuyener, L. van Thiel, A. Dikhtiarenko, J. Ruiz-Martinez, B.M. Weckhuysen, J. Gascon, F. Kapteijn, Methanol-to-olefins process over zeolite catalysts with DDR topology: effect of composition and structural defects on catalytic performance, Catalysis Science \& Technology, 6 (2016) 2663-2678.

[69] H.E. Bergna, The colloid chemistry of silica, in, American Chemical Society, Washington, DC (United States), 1994.

[70] P.L.J. Gunter, J.W. Niemantsverdriet, F.H. Ribeiro, G.A. Somorjai, Surface Science Approach to Modeling Supported Catalysts, Catalysis Reviews, 39 (1997) 77-168.

[71] M.J. Nash, A.M. Shough, D.W. Fickel, D.J. Doren, R.F. Lobo, High-Temperature Dehydrogenation of Brønsted Acid Sites in Zeolites, Journal of the American Chemical Society, 130 (2008) 2460-2462.

[72] C.C. Williams, J.G. Ekerdt, Infrared spectroscopic characterization of molybdenum carbonyl species formed by ultraviolet photoreduction of silica-supported molybdenum (VI) in carbon monoxide, The Journal of Physical Chemistry, 97 (1993) 6843-6852.

[73] N. Kosinov, F.J.A.G. Coumans, E.A. Uslamin, A.S.G. Wijpkema, B. Mezari, E.J.M. Hensen, Methane Dehydroaromatization by Mo/HZSM-5: Mono- or Bifunctional Catalysis?, ACS Catalysis, (2016) 520-529.

[74] J. Yang, D. Ma, F. Deng, Q. Luo, M. Zhang, X. Bao, C. Ye, Solid state 13C NMR studies of methane dehydroaromatization reaction on Mo/HZSM-5 and W/HZSM-5 catalysts, Chem. Commun., (2002) 3046-3047.

[75] H. Zheng, D. Ma, X. Liu, W. Zhang, X. Han, Y. Xu, X. Bao, Methane dehydroaromatization over Mo/HZSM-5: A study of catalytic process, Catal Lett, 111 (2006) 111-114.

[76] K. Kim, T. Lee, Y. Kwon, Y. Seo, J. Song, J.K. Park, H. Lee, J.Y. Park, H. Ihee, S.J. Cho, R. Ryoo, Lanthanum-catalysed synthesis of microporous 3D graphene-like carbons in a zeolite template, Nature, 535 (2016) 131.

[77] H. Okamoto, R. Eguchi, S. Hamao, H. Goto, K. Gotoh, Y. Sakai, M. Izumi, Y. Takaguchi, S. Gohda, Y. Kubozono, An Extended Phenacene-type Molecule, [8]Phenacene: Synthesis and Transistor Application, Scientific Reports, 4 (2014) 5330.

[78] M.I. Zaki, B. Vielhaber, H. Knoezinger, Low-temperature carbon monoxide adsorption and state of molybdena supported on alumina, titania, ceria, and zirconia. An infrared spectroscopic investigation, The Journal of Physical Chemistry, 90 (1986) 3176-3183.

[79] J. Raskó, J. Kiss, Infrared study of the adsorption of $\mathrm{CO}$ and $\mathrm{CH} 3$ on silica-supported $\mathrm{MoO} 3$ and Mo2C catalysts, Applied Catalysis A: General, 253 (2003) 427-436.

[80] W. Wu, Z. Wu, C. Liang, P. Ying, Z. Feng, C. Li, An IR study on the surface passivation of Mo2C/Al2O3 catalyst with O2, H2O and CO2, Physical Chemistry Chemical Physics, 6 (2004) 56035608.

[81] L. Chen, L. Lin, Z. Xu, T. Zhang, Q. Xin, P. Ying, G. Li, C. Li, Fourier Transform-Infrared Investigation of Adsorption of Methane and Carbon Monoxide on HZSM-5 and Mo/HZSM-5 Zeolites at Low Temperature, Journal of Catalysis, 161 (1996) 107-114.

[82] I. Vollmer, G. Li, I. Yarulina, N. Kosinov, E.J. Hensen, K. Houben, D. Mance, M. Baldus, J. Gascon, F. Kapteijn, Relevance of the Mo-precursor state in H-ZSM-5 for methane dehydroaromatization, Catalysis Science \& Technology, 8 (2018) 916-922.

[83] S. Liu, L. Wang, R. Ohnishi, M. Ichikawa, Bifunctional Catalysis of Mo/HZSM-5 in the Dehydroaromatization of Methane to Benzene and Naphthalene XAFS/TG/DTA/MASS/FTIR Characterization and Supporting Effects, Journal of Catalysis, 181 (1999) 175-188. 
[84] H.S. Lacheen, E. Iglesia, Stability, structure, and oxidation state of Mo/H-ZSM-5 catalysts during reactions of $\mathrm{CH} 4$ and $\mathrm{CH} 4-\mathrm{CO} 2$ mixtures, Journal of Catalysis, 230 (2005) 173-185.

[85] J.-Z. Zhang, M.A. Long, R.F. Howe, Molybdenum ZSM-5 zeolite catalysts for the conversion of methane to benzene, Catalysis Today, 44 (1998) 293-300.

[86] N. Kosinov, E.A. Uslamin, F.J.A.G. Coumans, A.S.G. Wijpkema, R.Y. Rohling, E.J.M. Hensen, Structure and Evolution of Confined Carbon Species during Methane Dehydroaromatization over Mo/ZSM-5, ACS Catalysis, (2018) 8459-8467. 